\title{
Andrographolide induces apoptosis in human osteosarcoma cells via the ROS/JNK pathway
}

\author{
SHENGDONG WANG ${ }^{1,2^{*}}$, HENGYUAN LI $^{1,2^{*}}$, SHI CHEN $^{1}$, ZENAN WANG $^{1,2}$,

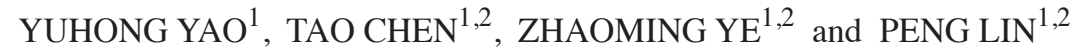 \\ ${ }^{1}$ Musculoskeletal Tumor Center, Department of Orthopedics, \\ The Second Affiliated Hospital of Zhejiang University School of Medicine; \\ ${ }^{2}$ Institute of Orthopedic Research, Zhejiang University, Hangzhou, Zhejiang 310009, P.R. China
}

Received November 7, 2019; Accepted March 11, 2020

DOI: 10.3892/ijo.2020.5032

\begin{abstract}
Osteosarcoma is the most common primary malignant tumor of the bone and the long-term survival of patients with this disease has remained unsatisfactory over the past several decades. Andrographolide, a traditional drug used in Chinese medicine, has been found to exert a significant antitumor effect against several types of cancer. However, relatively little is known about the effect of andrographolide on osteosarcoma and the underlying mechanisms. In the present study, it was shown that andrographolide inhibited osteosarcoma cell proliferation by arresting the cell cycle at the G2/M phase and increasing caspase-mediated apoptosis. Furthermore, treatment with andrographolide induced JNK activation and increased production of reactive oxygen species (ROS). The andrographolide-triggered apoptosis in osteosarcoma cells was partly abrogated by a JNK inhibitor and completely reversed by a ROS scavenger. Additionally, JNK activation and cell cycle arrest at the G2/M phase were prevented by administration of an ROS scavenger. In vivo, it was also found that andrographolide inhibited tumor growth by increasing the levels of ROS and activating JNK; thus inducing cytotoxicity in primary osteosarcoma cells. Together, the results of the present study suggest that andrographolide caused G2/M arrest and induced cell apoptosis via regulation of the ROS/JNK signaling pathway in osteosarcoma cells. Thus, andrographolide may serve as a promising antitumor therapeutic agent against osteosarcoma.
\end{abstract}

Correspondence to: Dr Zhaoming Ye and Dr Peng Lin, Musculoskeletal Tumor Center, Department of Orthopedics, The Second Affiliated Hospital of Zhejiang University School of Medicine, Building 1, 88 Jiefang Road, Hangzhou, Zhejiang 310009, P.R. China E-mail: yezhaoming@zju.edu.cn

E-mail: linpengg@zju.edu.cn

${ }^{*}$ Contributed equally

Key words: osteosarcoma, andrographolide, apoptosis, cell cycle, reactive oxygen species, JNK

\section{Introduction}

Osteosarcoma is the most common primary osteogenic malignant tumor in childhood and adolescence with a prevalence of 3 cases per million individuals annually worldwide $(1,2)$. The 5 -year survival rate of osteosarcoma patients has improved to $60-70 \%$ since 1970 s due to the development of advanced radical treatments and multi-agent chemotherapeutics; however, the survival rate has remained unaltered over the past several decades (3). Additionally, the 5-year survival rate of patients with recurrent or metastatic osteosarcoma is only $20 \%$ (4), and current therapies have exhibited limited efficacy. Osteosarcoma remains the second highest cause of cancer-related mortality among children and adolescents $(5,6)$, underscoring a critical need for the development of novel therapeutic strategies.

A number of natural plant-derived ingredients have been shown to exhibit promising antitumor therapeutic properties and are being evaluated in pre-clinical and clinical experiments (7-9). Andrographolide has been widely used for $>60$ years for its extensive therapeutic properties with minimal adverse side-effects $(10,11)$. Andrographolide exhibits significant cytotoxic effects against various cancer cell lines by inhibiting cell cycle progression, reducing cell invasion and inducing apoptosis (12-14). It has previously been reported that andrographolide treatment results in the apoptosis of human leukemic cells through the mitochondrial-mediated pathway (15). It has previously been demonstrated that andrographolide inhibits the proliferation of prostate cancer cells by inducing G2/M and G1 phase arrest, and initiating caspase-8-mediated mitochondrial apoptosis (16). However, the effect of andrographolide on osteosarcoma and the detailed underlying molecular mechanisms have not yet been elucidated.

Apoptosis, also known as type I programmed cell death, is a very orderly process during which the genome of the cell is broken down, the cell is fragmented into smaller sections, and the debris are consumed by nearby cells (phagocytes) that 'clean up' the cell fragments (17). Apoptosis serves a significant role in the chemotherapy of various types of cancer (18). Reactive oxygen species (ROS), active forms of oxygen, generated as by-products of cellular metabolism, possess 
toxic effects on a variety of molecular targets including lipids, DNA and proteins in most cells (19). Notably, cancer cells have been found to be more sensitive to damage by ROS products since they exhibit increased oxidative stress (20). Accumulating evidence indicates that ROS are involved in various signaling pathways and serve a key role in inducing cell apoptosis (21-24). Excessive amounts of ROS can affect multiple signaling pathways, such as MAPK family members, including JNK, p38 and ERK (25). JNK is a stress-activated protein kinase of the MAPK family, and serves a critical role in a number of cellular events, including apoptosis (26). Therefore, targeting ROS/JNK may be an effective method for treating cancer.

The detailed mechanisms responsible for the antitumor effects of andrographolide remain uncertain. It has been shown that andrographolide can induce cytotoxicity and cell cycle arrest in breast cancer, prostate cancer, laryngeal cancer and gastric cancer by upregulating ROS production, leading to programmed cell death (27-30). Andrographolide has also been found to induce human hepatoma cell death through JNK activation (31). Moreover, a recent study reported that the ROS/JNK pathway was involved in the andrographolide-induced cell death of HeLa cells (32). However, whether andrographolide can induce apoptosis of osteosarcoma cells, and whether the antitumor effect is mediated via the ROS/JNK pathway remains unknown, to the best of our knowledge.

In the present study, the antitumor effects of andrographolide against osteosarcoma cells in vitro and in vivo were demonstrated. The possible molecular mechanisms were further explored, and it was demonstrated that andrographolide induced G2/M phase arrest and the apoptosis of osteosarcoma cells via the ROS/JNK signaling pathway.

\section{Materials and methods}

Reagents and antibodies. Andrographolide (>98\%) was purchased from Selleck Chemicals and dissolved in DMSO (Sigma-Aldrich; Merck KGaA) at a concentration of 100 mM. N-Acetyl-L-cysteine (NAC) and SP600125 (SP) were purchased from Sigma-Aldrich; Merck KGaA. The molecular formula of andrographolide is $\mathrm{C} 20 \mathrm{H} 30 \mathrm{O} 5$ and its molecular weight is 350.45. FBS, DMEM, RPMI-1640 medium, penicillin, streptomycin, PBS and $0.25 \%$ trypsin were obtained from Gibco; Thermo Fisher Scientific, Inc. The following antibodies were used for western blot analysis: Poly(ADP-ribose) polymerase (PARP, cat. no. 9542), cleaved caspase-3 (cat. no. 9664), cleaved caspase-8 (cat. no. 9496), cleaved caspase-9 (cat. no. 9505), phospho-JNK (cat. no. 4668), JNK (cat. no. 9252) and GAPDH (cat. no. 5174). These were obtained from Cell Signaling Technology, Inc.

Cells and cell culture. The osteosarcoma cell lines, HOS, U2OS, SAOS-2 and MG-63, were purchased from the Shanghai Institute of Cell Biology, Chinese Academy of Sciences (Shanghai, China). The HOS, SAOS-2 and MG-63 cells were cultured in DMEM (Gibco; Thermo Fisher Scientific, Inc.) and the U2OS cells were cultured in RPMI-1640 medium (Gibco; Thermo Fisher Scientific, Inc.). A total of 6 patients with osteosarcoma from the Musculoskeletal Tumor Center, Department of Orthopedics, The Second Affiliated Hospital of
Zhejiang University School of Medicine were included in the present study. The cohort included four males and two females, ranging with a median age of 20 (age range, 12-28). Tumor specimens from osteosarcoma patients were mechanically disaggregated using razor blades at $37^{\circ} \mathrm{C}$ for $2 \mathrm{~h}$ in DMEM with collagenase type IV $(2 \mathrm{mg} / \mathrm{ml})$, DNase $(0.1 \mathrm{mg} / \mathrm{ml})$, hyaluronidase $(0.1 \mathrm{mg} / \mathrm{ml})$ and BSA $(2 \mathrm{mg} / \mathrm{ml})$ (all from Sigma-Aldrich; Merck KGaA). Cell suspensions were passed through $70-\mu \mathrm{m}$ filters to remove aggregates and then cultured in DMEM. All media were supplemented with $10 \%$ FBS, $100 \mathrm{U} / \mathrm{ml}$ penicillin and $100 \mu \mathrm{g} / \mathrm{ml}$ streptomycin. Cells were maintained at $37^{\circ} \mathrm{C}$ in a $5 \% \mathrm{CO}_{2}$ incubator.

Written informed consent was obtained from each patient or their legal guardians where required and the study was approved by the Human Research Ethics Committees of the Second Affiliated Hospital, School of Medicine, Zhejiang University (Hangzhou, China).

Cell viability assay. Briefly, HOS, U2OS, SAOS-2 and MG-63 cells were seeded in 96-well tissue culture plates for one day at a density of $4 \times 10^{3}$ cells/well. Following treatment with various concentrations of andrographolide $(0,20,40$ and $80 \mu \mathrm{M})$ for $12,24,48$ and $96 \mathrm{~h}$, cell viability was evaluated using an MTS kit (cellTiter96AQ; Promega Corporation) according to the manufacturer's protocol. The optical density value was measured on an MR7000 microplate reader (Dynatech) at $490 \mathrm{~nm}$.

Colony formation assay. Colony formation assays were performed to assess the effect of andrographolide on osteosarcoma cell clonal ability. Cells were seeded at 100/well in 6-well plates and treated with various concentrations of andrographolide $(0,1.25,2.5,5$ and $10 \mu \mathrm{M})$ for 2 weeks until visible colonies were observed. The cells were then washed with PBS twice and fixed with $4 \%$ paraformaldehyde at room temperature for $15 \mathrm{~min}$. After washing twice again, the cells were stained with $0.1 \%$ crystal violet at room temperature for $15 \mathrm{~min}$. Finally, the plates were imaged, and the colonies were counted under a light microscope (magnification, $\mathrm{x} 4$ ).

Morphological apoptosis. To determine the apoptotic morphological changes, cells were treated with $40 \mu \mathrm{M}$ andrographolide for $24 \mathrm{~h}$ and then stained with Hoechst 33258 (Beyotime Institute of Biotechnology) for $10 \mathrm{~min}$ at room temperature. After washing twice, cell morphology was observed using a fluorescence microscope (magnification, x10; Olympus Corporation) to determine chromatin condensation.

Cell cycle analysis. Cells were plated at 3x105/well in 6 -well plates and treated with andrographolide $(0,20$, 40 and $80 \mu \mathrm{M}$ ) for $24 \mathrm{~h}$. The cells were then trypsinized and fixed with cold $75 \%$ ethanol at $-20^{\circ} \mathrm{C}$ overnight. The cells were stained with buffer containing propidium iodide and RNase (BD Biosciences) at room temperature for $15 \mathrm{~min}$ and analyzed using a FACSCalibur (BD Biosciences) flow cytometer and ModFit LT software (version 3.2; Verity Software).

Apoptosis analysis. A total of $2.5 \times 10^{5}$ cells/well were plated in 6-well plates. Following treatment with andrographolide $(0-80 \mu \mathrm{M})$ for $24 \mathrm{~h}$, the cells were incubated with Annexin V-PE 
and 7-AAD for $15 \mathrm{~min}$ at $37^{\circ} \mathrm{C}$ in the dark. Subsequently, cells were washed and resuspended in $300 \mu \mathrm{l} \mathrm{PB}$, assessed using a flow cytometer (FACSCalibur, BD Biosciences) and the data were analyzed using CellQuest ${ }^{\mathrm{TM}}$ Pro version 5.1 (Becton, Dickinson and company).

Western blot analysis. HOS and U2OS cells were seeded in $60-\mathrm{mm}$ dishes. Following treatment with andrographolide for $24 \mathrm{~h}$, the cells were harvested, washed and resuspended in RIPA lysis buffer (Beyotime Institute of Biotechnology) with phenylmethanesulfonyl fluoride for $30 \mathrm{~min}$ on ice. The lysates were centrifuged at $4^{\circ} \mathrm{C}$ and $13,000 \mathrm{x}$ g for $15 \mathrm{~min}$. The protein concentrations were determined using a bicinchoninic acid protein assay kit (Beyotime Institute Biotechnology). Equal quantities of protein $(40 \mu \mathrm{g})$ were loaded on an SDS gel $(10 \%$ or $12 \%)$, resolved using SDS-PAGE and transferred to PVDF membranes (EMD Millipore). Membranes were blocked with TBS-Tween (TBST) containing 5\% skimmed milk, and then incubated overnight at $4^{\circ} \mathrm{C}$ with the primary antibodies. Subsequently, the membrane was washed with TBST, and incubated for $1 \mathrm{~h}$ at room temperature with a horseradish peroxidase-conjugated goat secondary anti-rabbit IgG (Boster Biological Technology; cat. no. BA1054). The membranes were incubated with an enhanced chemiluminescence kit (EMD Millipore), and the protein bands were then visualized using a ChemiDoc imaging system (Bio-Rad Laboratories, Inc.). Densitometry analysis was performed using ImageJ (Version 1.46; National Institutes of Health)

Measurement of mitochondrial membrane potential (MMP). JC-1 fluorescent probe (Beyotime Institute of Biotechnology) was used to measure MMP. Briefly, cells were plated at a density of $2.5 \times 10^{5} /$ well in 6 -well plates and treated with andrographolide $(0-80 \mu \mathrm{M})$ for $24 \mathrm{~h}$. The cells were then collected and incubated with $\mathrm{JC}-1$ for $20 \mathrm{~min}$ at $37^{\circ} \mathrm{C}$. Subsequently, the stained cells were washed and analyzed using a flow cytometry.

Measurement of ROS generation. ROS assays using DCFH-DA (Beyotime Institute of Biotechnology) were used to measure intracellular ROS. Briefly, the cells were treated with andrographolide $(0-80 \mu \mathrm{M})$ for $12 \mathrm{~h}$ prior to incubation with DCFH-DA $(10 \mu \mathrm{M})$ for $30 \mathrm{~min}$ at $37^{\circ} \mathrm{C}$. Subsequently, the stained cells were detected using fluorescence microscopy (magnification, x10) and flow cytometry. ROS production in vivo was determined using dihydroethidium (DHE) as described previously (33). Briefly, $24 \mathrm{~h}$ before sacrifice, each mouse received a $200 \mu \mathrm{l}$ intravenous injection of DHE at $25 \mathrm{mg} / \mathrm{kg}$.

Animal experimental design. Female Balb/c-nu mice (5 weeks old, $n=15$ ) were purchased from the Shanghai Laboratory Animal Center of Chinese Academy of Sciences. HOS cells were transfected with luciferase (HOS-Luc) using lentivirus for in vivo imaging. For lentiviral infection, HOS cells were incubated with lentiviral luciferase particles [pLV-Puro-CMV (Luc); Hanbio Biotechnology, Co., Ltd.] in the presence of $5 \mu \mathrm{g} / \mathrm{ml}$ polybrene (Hanbio Biotechnology, Co., Ltd.). After $12 \mathrm{~h}$, the infection medium was discarded, and the cells were cultured with fresh medium for 3 days before being screened using puromycin (4 $\mu \mathrm{g} / \mathrm{ml}$; Sigma-Aldrich; Merck KGaA) and then passaged for use in subsequent experiments. Tumor xenografts were established by a subcutaneous injection of $5 \times 10^{6} \mathrm{HOS}-\mathrm{Luc}$ cells suspended in $100 \mu \mathrm{l}$ PBS into the flanks of mice. Tumor size was monitored every two days and calculated as follows: Length $\mathrm{x}$ width $2 / 2$. When the tumors had grown for 10 days, reaching $\sim 50 \mathrm{~mm}^{3}$, the mice were randomly divided into three groups, each of which contained five mice. The three groups of mice received intraperitoneal injections with $100 \mu 1$ 1\% DMSO in PBS, or a low or high concentration of andrographolide every two days, respectively. Tumor sizes and body weights were measured every two days to observe dynamic variations. Tumor inhibition rate was calculated as follows: (1 - volume in experimental group/volume in control group) x $100 \%$. After two weeks of therapy, all mice were euthanized, and tumors were excised and fixed in $10 \%$ neutral-buffered formalin for $24 \mathrm{~h}$ at $4^{\circ} \mathrm{C}$ for further analysis. The animal experiments were approved by the Animal Care and Use Committee of Zhejiang University, China.

Tumor histology. Tumor specimens were cut into serial sections $(3-\mu \mathrm{m}$-thick) after fixing with formalin and embedding in paraffin. The slides were hydrated using a gradient of ethanol solutions $(100 \%, 100 \%, 95 \%, 85 \%$ and $75 \%$ ethanol, followed by PBS; 5 min each). Subsequently, the slides were stained with hematoxylin at room temperature for $15 \mathrm{~min}$, and then immersed in $1 \%$ hydrochloric acid in $75 \%$ ethanol for 30 sec. The slides were then washed and stained with eosin at room temperature for $5 \mathrm{~min}$. Following dehydration, the slides were immersed in xylene.

Immunohistochemical analysis. Formalin-fixed and paraffin-embedded tumor specimens were cut into serial sections of $3 \mu \mathrm{m}$ thickness. Slides were treated with $3 \% \mathrm{H}_{2} \mathrm{O}_{2}$ for 15 min to block endogenous peroxidase activity. Antigen retrieval was performed by boiling in sodium citrate buffer ( $\mathrm{pH}$ 6.0) for $10 \mathrm{~min}$. The slides were then incubated with $10 \%$ goat serum (cat. no. SL038, Beijing Solarbio Science \& Technology Co., Ltd.) at room temperature for $30 \mathrm{~min}$. Slides were incubated with cleaved caspase-3 (1:50) and phospho-JNK (1:50) antibodies at $4^{\circ} \mathrm{C}$ overnight and then washed with PBS three times. Subsequently, the slides were treated with a biotin-labeled secondary antibody (1:50) at room temperature for $30 \mathrm{~min}$ prior to incubation with DAB (Sigma-Aldrich; Merck $\mathrm{KGaA}$ ) at room temperature for $\sim 30 \mathrm{sec}$. Then the slides were stained with hematoxylin at room temperature for $15 \mathrm{~min}$ and the images were obtained using a light microscope (magnification, x20).

Statistical analysis. All experiments were performed in a minimum of triplicates. Quantitative data are expressed as the mean \pm standard deviation, and the significance of the differences between treatment groups were determined using one-way ANOVA with a post hoc Dunnett's test or a Student's t-test. $\mathrm{P}<0.05$ was considered to indicate a statistically significant difference.

\section{Results}

Andrographolide inhibits the proliferation of osteosarcoma cells in a time-and dose-dependent manner. To evaluate the 
A
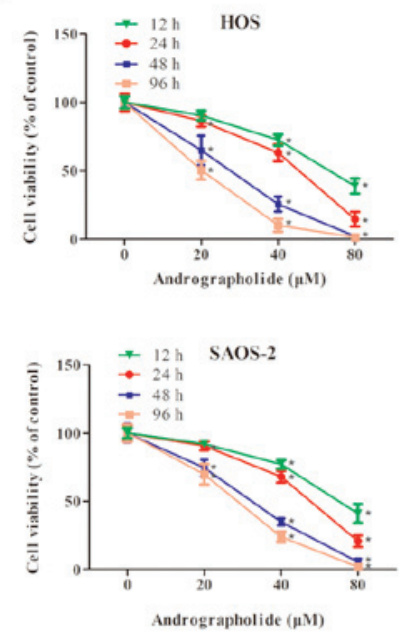

$\mathrm{D}$
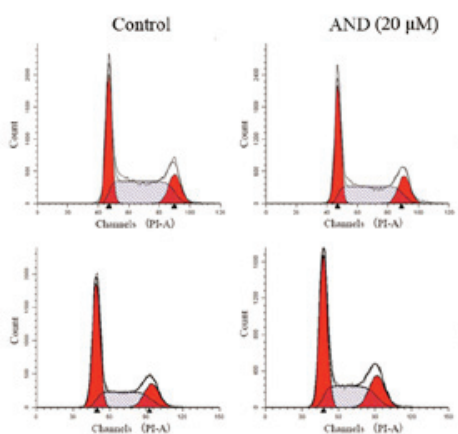
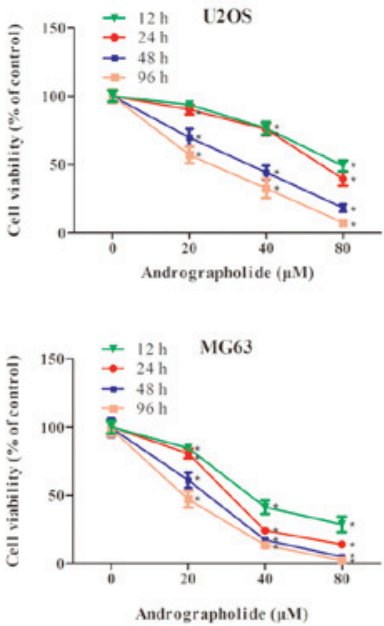
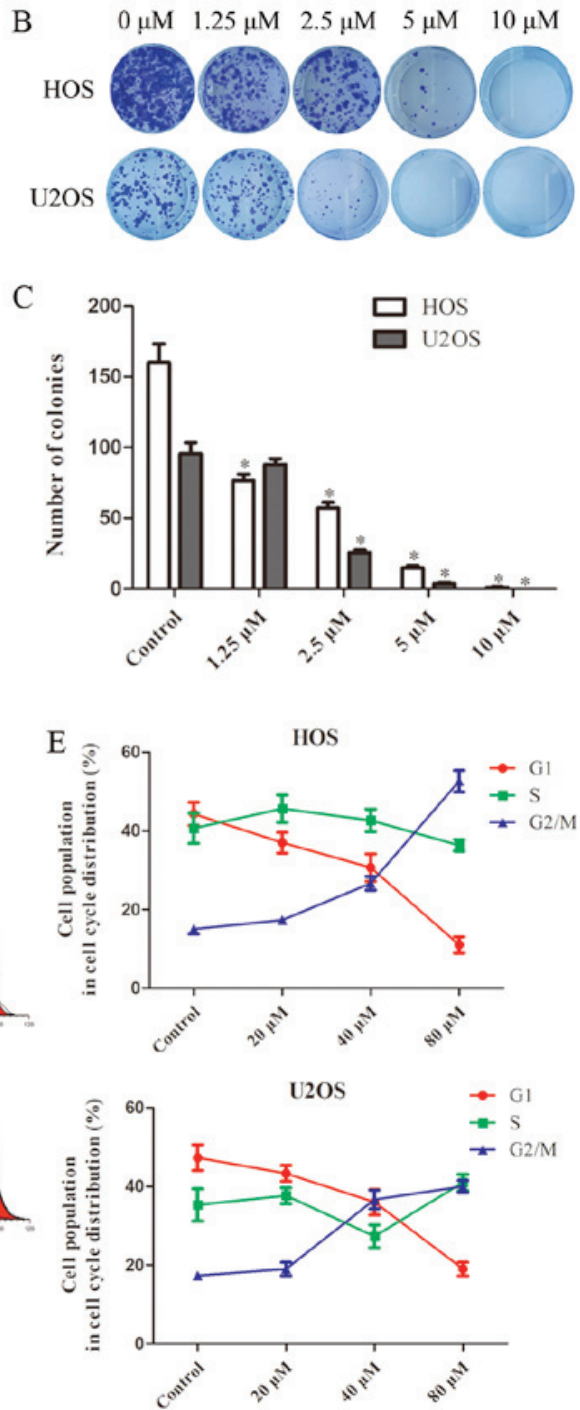

Figure 1. AND reduces the proliferation of osteosarcoma cells and induces G2/M phase cell cycle arrest. (A) Osteosarcoma cells were treated with various concentrations of AND for 24 and $48 \mathrm{~h}$, and the effects of AND on proliferation was measured using an MTS assay. Each experiment was performed in triplicate. (B) Representative images and (C) quantitative analysis of the colony formation assays of HOS and U2OS cells treated with various concentrations of AND. (D and E) AND induced cell cycle arrest in osteosarcoma cells. Cells were treated with the indicated concentration of AND for $24 \mathrm{~h}$ and then analyzed by flow cytometry. Each experiment was performed three times independently. ${ }^{*} \mathrm{P}<0.05$ vs. control. AND, andrographolide.

effect of andrographolide on the growth of osteosarcoma cells, HOS, U2OS, SAOS-2 and MG-63 cell lines were treated with various concentrations of andrographolide $(0-80 \mu \mathrm{M})$ for 12 , 24, 48 and 96 h (Fig. 1A). Based on the results of MTS assay, the viability of the tumor cells was significantly reduced by andrographolide in a time- and dose-dependent manner, and the $\mathrm{IC}_{50}$ values for $24 \mathrm{~h}$ of treatment were $50.84 \mu \mathrm{M}$ for HOS cells, $68.42 \mu \mathrm{M}$ for U2OS cells, $55.27 \mu \mathrm{M}$ for SAOS-2 cells and $30.87 \mu \mathrm{M}$ for MG-63 cells. Although MG-63 seemed to be the most sensitive cell line, HOS and U2OS were selected for further studies as HOS cells are more suitable for use in animal studies $(23,34)$ and U2OS cells are more stable for use in the in vitro experiments used in the present study. Colony formation assays showed that fewer colonies were formed following andrographolide treatment (Fig. 1B and C).

Andrographolide treatment results in G2/M phase cell cycle arrest. To determine whether andrographolide reduced cell viability by inducing cell cycle arrest, cell cycle distribution of the cells treated with andrographolide was assessed. Exposure to andrographolide resulted in a marked increase in the proportion of cells in the G2/M phase, and a corresponding decrease in the proportion of cells in the G1 and $\mathrm{S}$ phases in both the HOS and U2OS cells (Fig. 1D and E). The percentage of cells in the G2 phase increased from 15.1 to $51.6 \%$ in the HOS, and from 17.2 to $39.6 \%$ in the U2OS cells.

Andrographolide increases mitochondrial-mediated apoptosis of osteosarcoma cells. To determine whether apoptosis was responsible for the reduced cell growth induced by andrographolide, Hoechst staining and flow cytometry assays were performed. The results showed that apoptotic chromatin condensation was clearly observed in the cells treated with andrographolide (Fig. 2A). To quantify apoptosis, tumor cells treated with the indicated concentrations of andrographolide were stained with Annexin V-PE/7-AAD. As shown in Fig. 2B and C, the proportion of apoptotic cells was negligible for the control cells, whereas exposure of the 
A
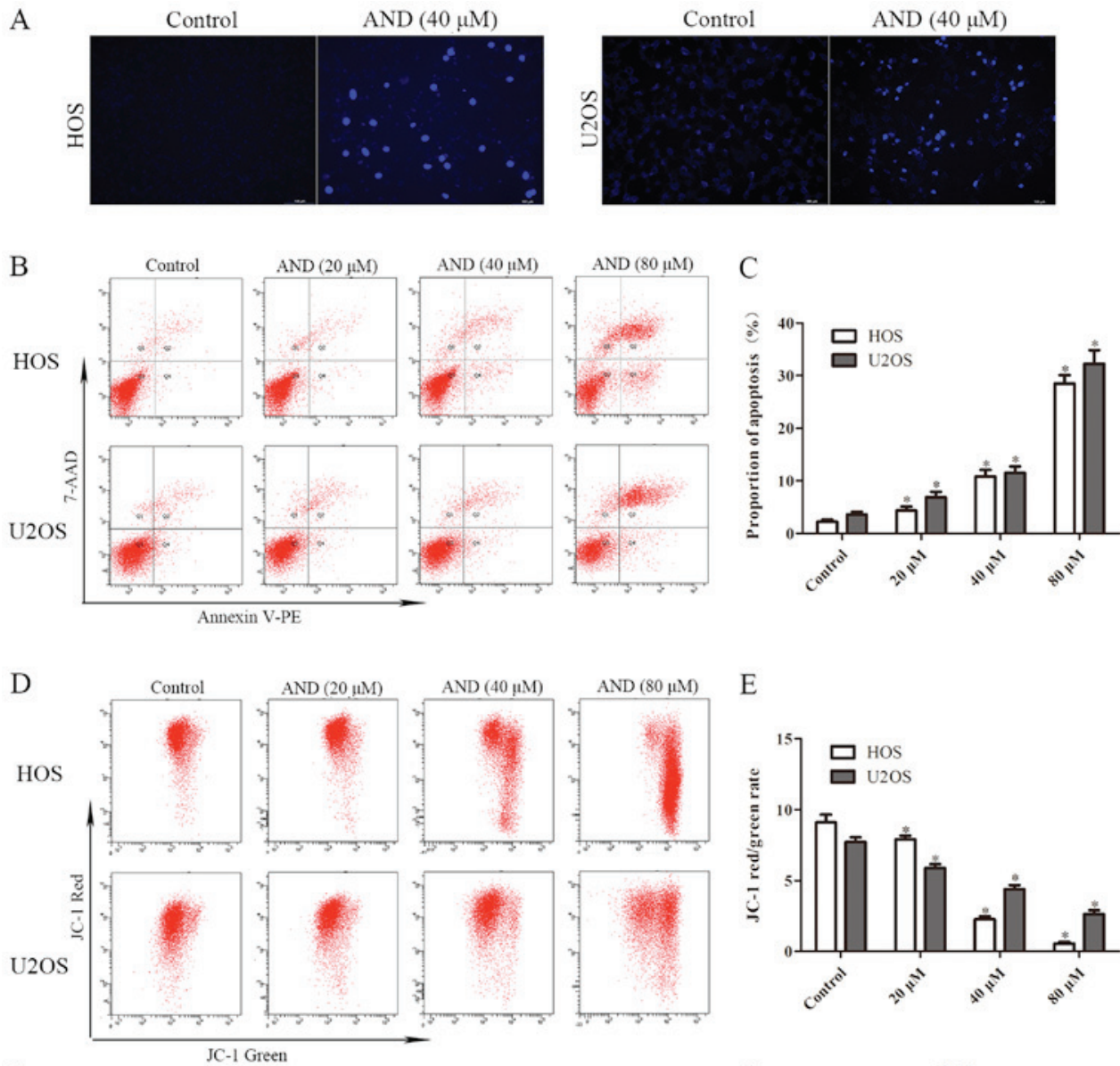

$\mathrm{E}$

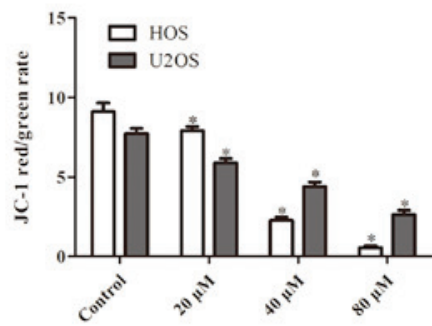

F
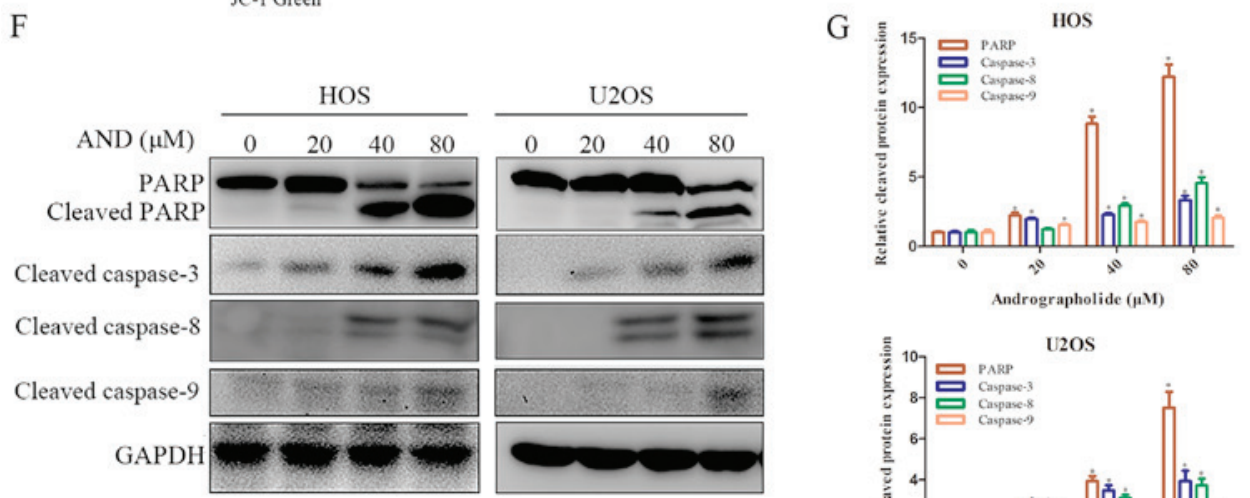

Figure 2. AND induces apoptosis in osteosarcoma cells. (A) HOS and U2OS cells were treated with AND, and the apoptotic morphological changes were evaluated by fluorescence microscopy using Hoechst 33258 staining. (B and C) HOS and U2OS cells were stained with Annexin V-PE/7-AAD following exposure to various concentrations of AND. Apoptosis was evaluated by flow cytometry. (D and E) Mitochondrial membrane potential was detected by flow cytometry using the JC-1 fluorescent probe. Changes in the JC-1 red/green ratio from three separate experiments are illustrated in the chart. (F) Cells were treated with various concentrations of AND for $24 \mathrm{~h}$ and the expression of cleaved PARP, caspase- $3,-8$ and -9 was examined by western blot analysis. (G) Histogram shows the relative cleaved protein expression of cells exposed to various concentrations of AND for $24 \mathrm{~h}$. "P<0.05 vs. control. AND, andrographolide; PARP, Poly(ADP-ribose) polymerase.

cells to andrographolide for $24 \mathrm{~h}$ resulted in a dose-dependent increase in the proportion of both early and late apoptotic cells. The effect of andrographolide on the mitochondria was also determined. MMP was shown to decrease significantly in the presence of andrographolide (Fig. 2D and E). Subsequently, the expression of a downstream apoptotic protein was measured. As shown in Fig. $2 \mathrm{~F}$ and $\mathrm{G}$, andrographolide significantly induced caspase- $3,-8$ and -9 activation, and resulted in PARP cleavage. Overall, these results suggest that andrographolide induces mitochondrial-mediated apoptosis.

Andrographolide induces apoptosis by promoting JNK activation. The role of JNK in andrographolide-induced apoptosis was investigated. The results revealed that phosphorylated JNK expression was increased by andrographolide in both the HOS and U2OS cells (Fig. 3C). To determine whether JNK 
A
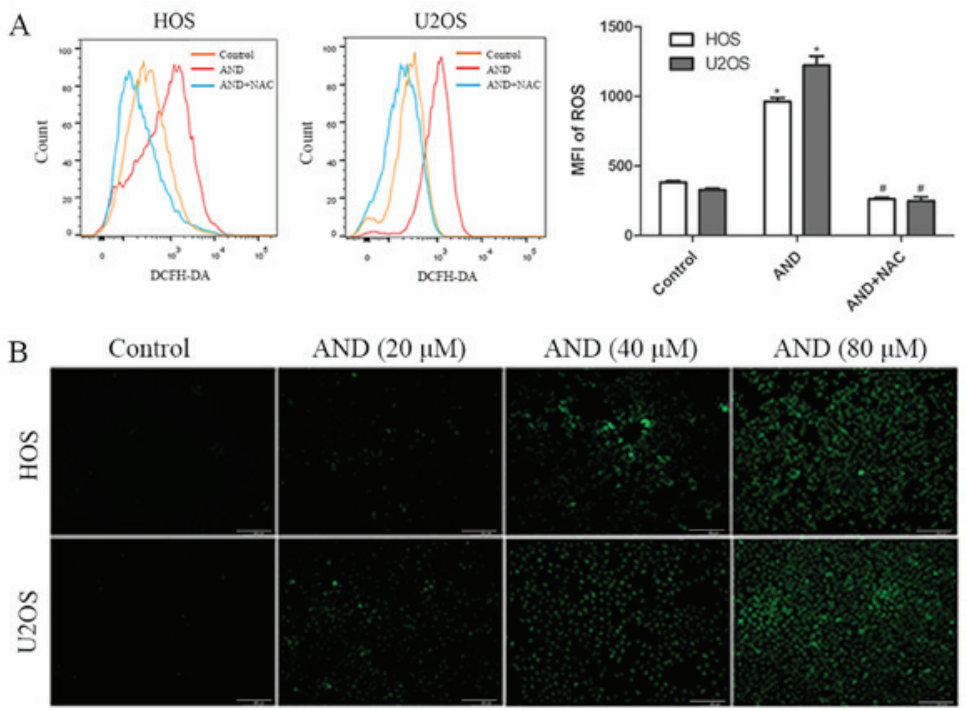

$\mathrm{C}$

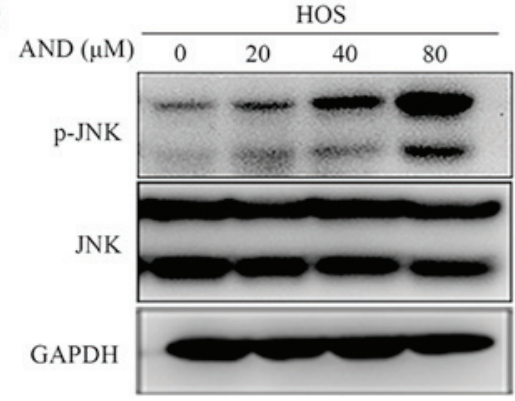

AND $(40 \mu \mathrm{M})$
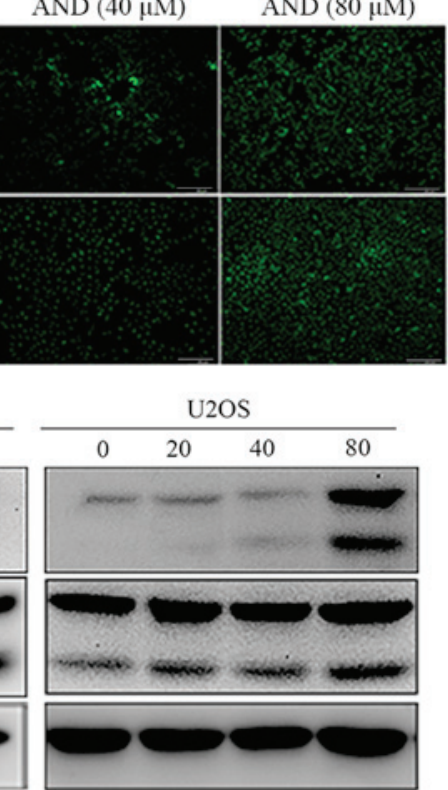

Figure 3. AND induces generation of ROS and JNK activation in osteosarcoma cells. (A and B) Cells were incubated with DCFH-DA for 30 min following treatment with AND for $12 \mathrm{~h}$. The levels of ROS were measured by flow cytometry and visualized by fluorescence microscopy. Histogram showing quantitative expression of ROS. Scale bar, $200 \mu \mathrm{m}$. ${ }^{*} \mathrm{P}<0.05$ vs. control; ${ }^{\sharp} \mathrm{P}<0.05$ vs. AND. (C) Cells were treated with various concentrations of AND for $24 \mathrm{~h}$ and the levels of p-JNK and JNK were determined by western blot analysis. AND, andrographolide; ROS, reactive oxygen species; p-JNK, phospho-JNK; MFI, mean fluorescence intensity.

activation contributes to andrographolide-induced apoptosis and G2/M phase arrest, SP600125 (SP), a specific JNK inhibitor, was used to block JNK phosphorylation. The MTS assays showed that andrographolide-induced cytotoxicity against osteosarcoma cells was reduced by SP (Fig. 4A). As shown by flow cytometry, SP also inhibited andrographolide-induced apoptosis and reduced mitochondrial depolarization (Fig. 4C-F). SP blocked JNK activation and inhibited the accumulation of apoptosis-related proteins (Fig. 4G). However, SP failed to reverse $\mathrm{G} 2 / \mathrm{M}$ phase cell cycle arrest caused by andrographolide (Fig. 4B). These results suggest that JNK activation is required for andrographolide-induced apoptosis, but was not involved in cell cycle arrest.

Andrographolide promotes ROS generation, which results in JNK activation and initiates andrographolide-induced apoptosis and G2/M phase cell cycle arrest. ROS have been reported to serve a significant role in mediating apoptosis and cell cycle arrest $(35,36)$, and also to promote the sustained activation of JNK (37), thus, the ROS levels were detected. ROS production was significantly increased by andrographolide treatment and the increased ROS production was completely blocked by NAC, an ROS scavenger (Fig. 3A). As shown in Fig. 3B, the results further revealed that ROS production was initiated by $20 \mu \mathrm{M}$ andrographolide and was significantly increased when cells were treated with $80 \mu \mathrm{M}$. MTS assays showed that NAC reduced the cell death caused by andrographolide (Fig. 4A). In addition, in contrast to the JNK inhibitor, NAC was found to have a notably more potent effect on reducing apoptosis and attenuating the decrease in MMP levels induced by andrographolide (Fig. 4C-F). Furthermore, NAC was demonstrated to completely inhibit andrographolide-induced increase in expression of apoptosis-associated proteins (Fig. 4G), and restore the andrographolide-induced increase in the proportion of cells in the G2/M phase (Fig. 4B). NAC significantly blocked JNK activation, and the JNK inhibitor did not exert a notable effect on ROS suppression (Fig. 4G and H). Together, these results suggest that ROS generation results in JNK phosphorylation and initiates andrographolide-induced apoptosis and cell cycle arrest.

Andrographolide inhibits the growth of osteosarcoma in vivo. To examine the in vivo effects of andrographolide on osteosarcoma growth, equal numbers of HOS-Luc cells were injected subcutaneously into nude mice. Once the tumors reached $\sim 50 \mathrm{~mm}^{3}$, the mice were treated with an intraperitoneal injection of control or andrographolide treatment every other day. Compared with the control, tumor growth in the groups receiving 15 and $30 \mathrm{mg} / \mathrm{kg}$ was decreased by 45.6 and $57.4 \%$, respectively, after 14 days of treatment (Fig. 5A-D). There was no difference in body weight according to the data (Fig. 5E). Tumor tissue was harvested 
A
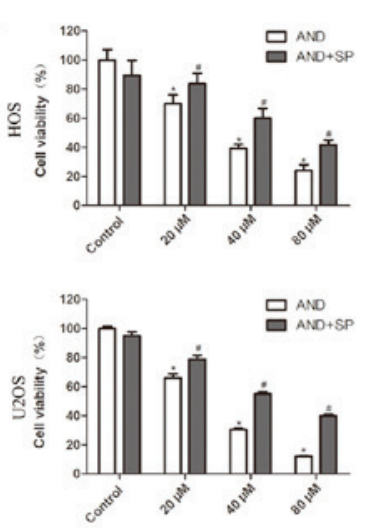

C

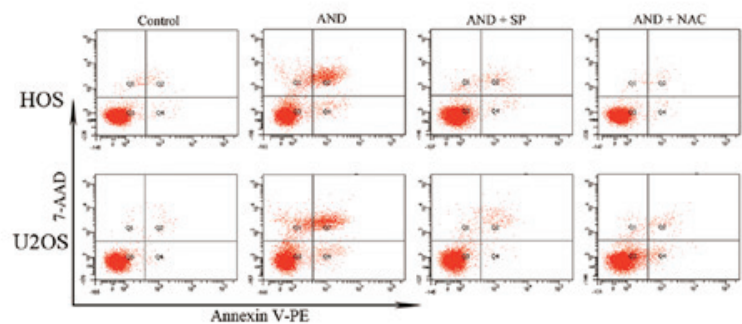

E

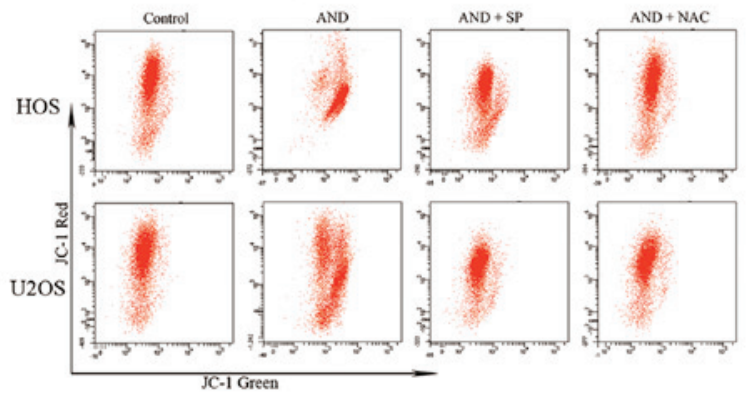

G

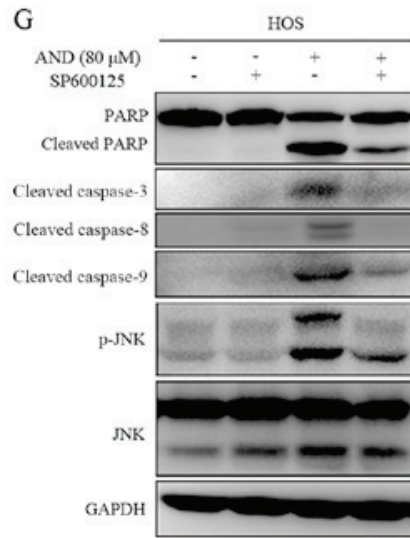

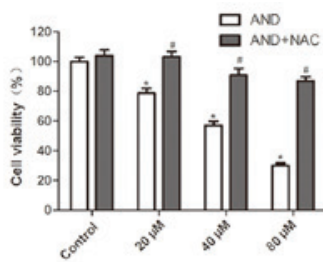
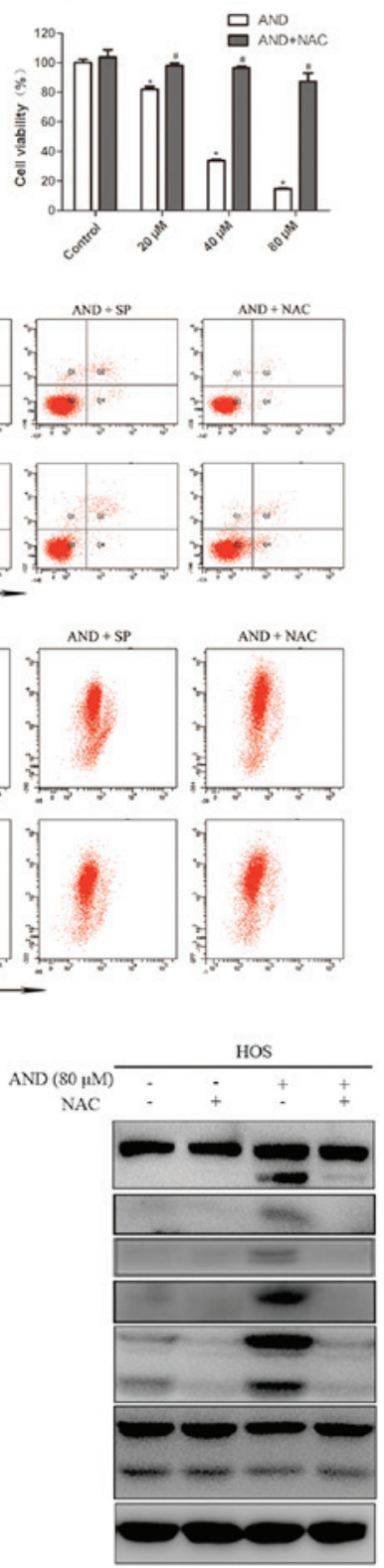

B

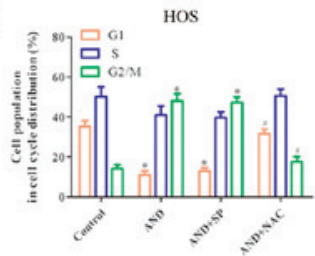

U2OS
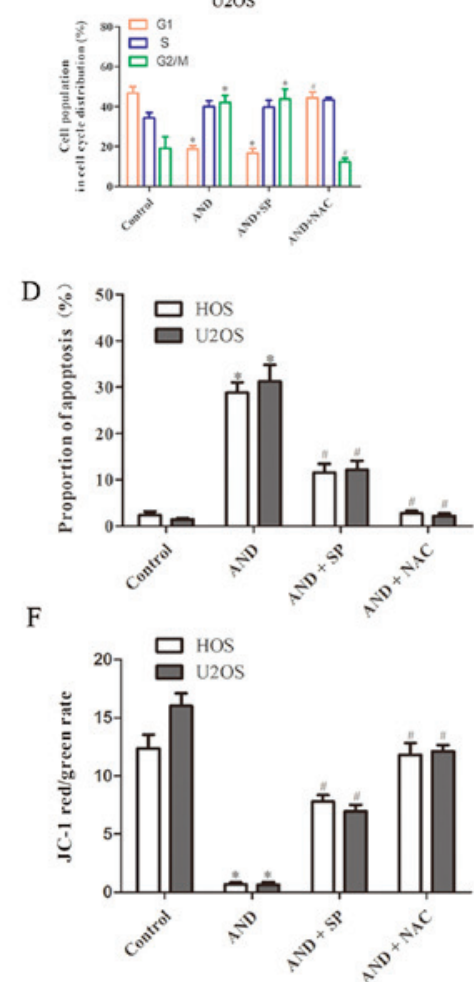

$\mathrm{H}$

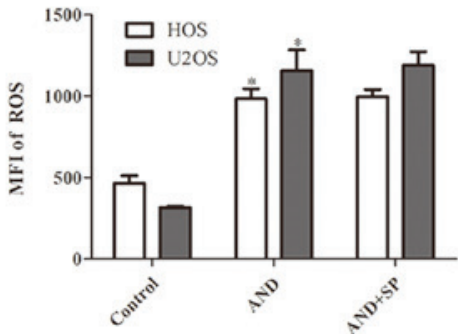

Figure 4. Roles of ROS and JNK in AND-induced G2/M cell cycle arrest and apoptosis of osteosarcoma cells. Cells were treated with SP600125 (40 $\mu$ M) or NAC $(5 \mu \mathrm{M})$ for $1 \mathrm{~h}$ prior to incubation with AND for $24 \mathrm{~h}$. (A) Cell proliferation was determined using an MTS assay. (B) Cell cycle distribution was evaluated by flow cytometry is shown in the histogram. (C and D) Apoptosis and (E and F) mitochondrial membrane potential were detected using flow cytometry. (G) Expression of apoptosis-related proteins, p-JNK and JNK was measured by western blot analysis. (H) Levels of ROS were estimated by flow cytometry. ${ }^{*} \mathrm{P}<0.05$ vs. control, ${ }^{\#} \mathrm{P}<0.05$ vs. AND treatment. AND, andrographolide; ROS, reactive oxygen species; SP, SP600125; NAC, N-Acetyl-L-cysteine; p-JNK, phospho-JNK; MFI, mean fluorescence intensity; PARP, Poly(ADP-ribose) polymerase.

from the control- and andrographolide-treated mice for further analysis. Upregulated levels of ROS were detected in tumor tissue from mice treated with andrographolide (Fig. 6A). Hematoxylin and eosin staining showed that the proportion of dead cells in the andrographolide-treated tumor tissue was higher (Fig. 6C). Both immunohistochemistry and western blot analysis showed that the expression levels of cleaved caspase-3 and phosphorylated JNK were increased by andrographolide treatment (Fig. 6B-D). All these data suggest that andrographolide inhibits the growth of osteosarcoma in vivo.

Andrographolide exerts similar antitumor effects on primary osteosarcoma cells as it does on cell lines. Primary osteosarcoma cells were obtained from six patients who suffered from osteosarcoma and were used to assess the effects of 


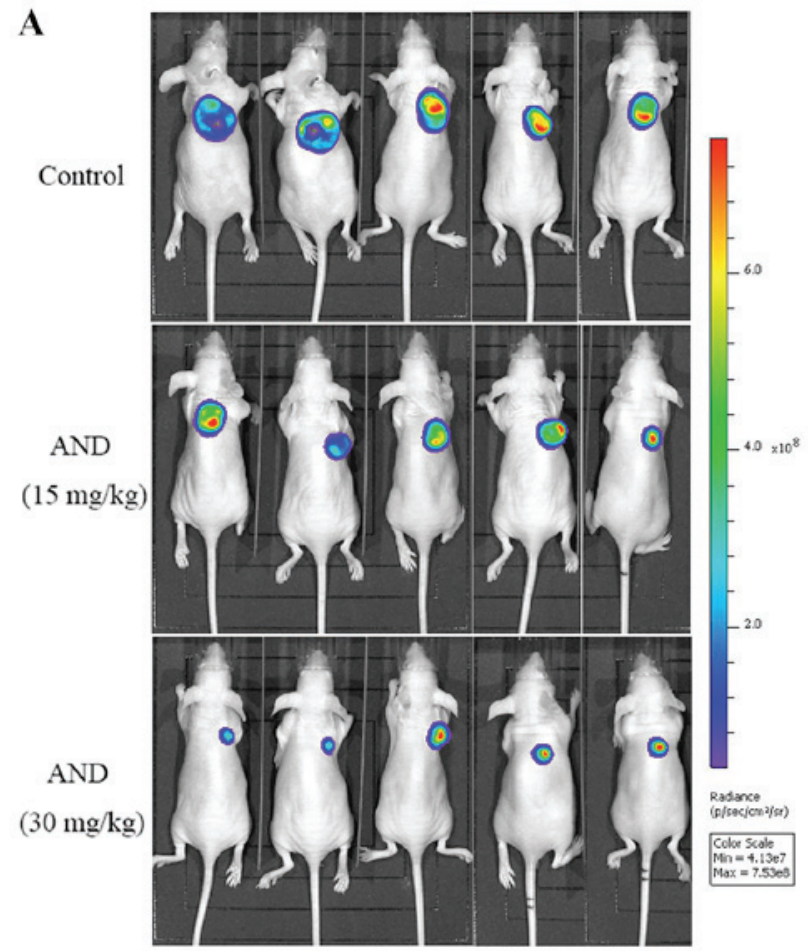

B

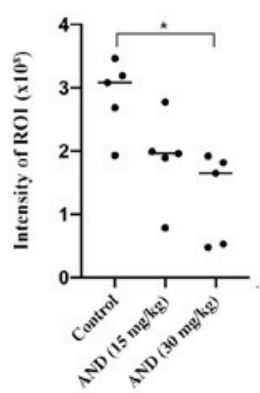

E

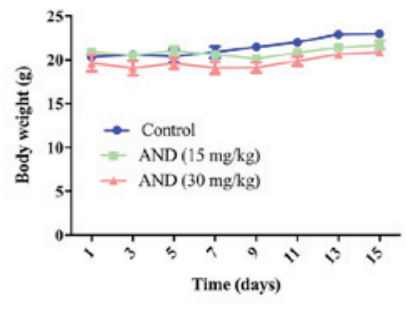

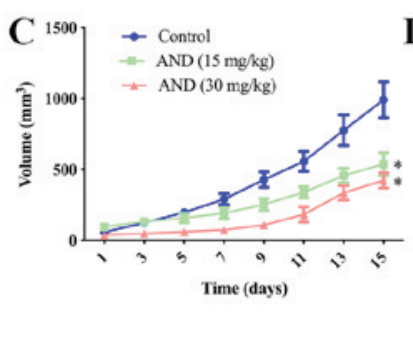

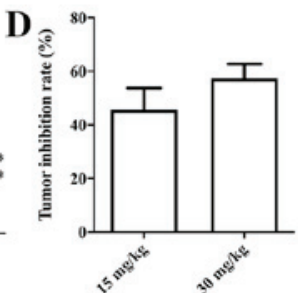

Figure 5. AND inhibits osteosarcoma growth in xenograft mice models. HOS-Luc cells were injected subcutaneously into the right flank of BALB/c-nu mice. Intraperitoneal administration of the vehicle or AND $(15$ or $30 \mathrm{mg} / \mathrm{kg})$ every second day commenced when the tumor volume reached $\sim 50 \mathrm{~mm}^{3}$. (A and B) Mice were imaged using in vivo imaging and tumor growth was evaluated by visualizing bioluminescence. The intensity of the ROI in mouse osteosarcoma models was measured and compared between the control and AND-treated groups. (C-E) Tumor sizes and body weights were measured every two days. Tumor inhibition rate is shown in the histogram. "P<0.05 vs. control. ROI, region of interest; AND, andrographolide; Luc, luciferase.

A

A Control

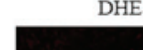

DHE

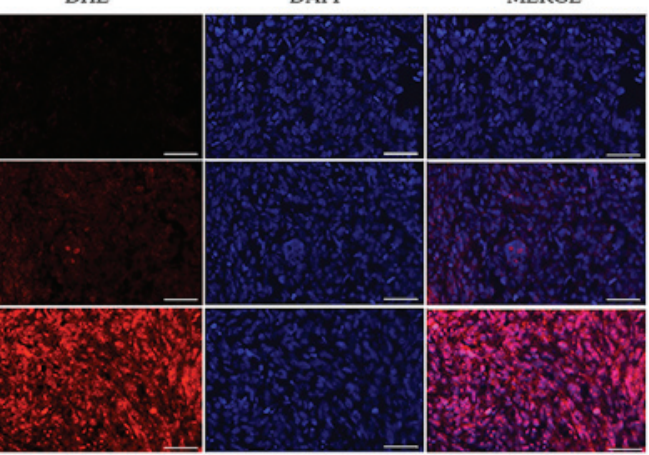

C

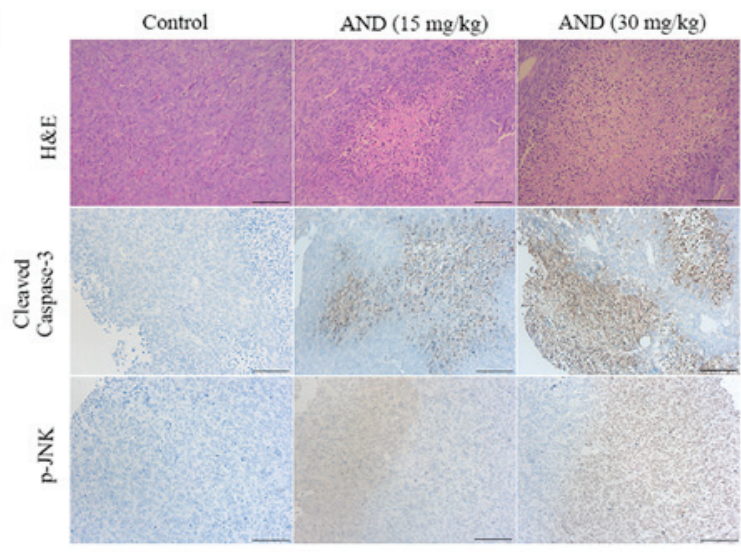

B

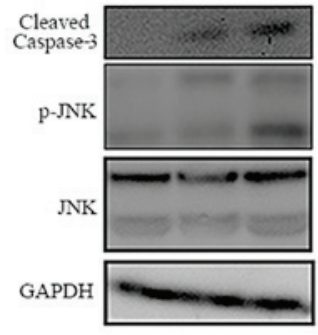

D
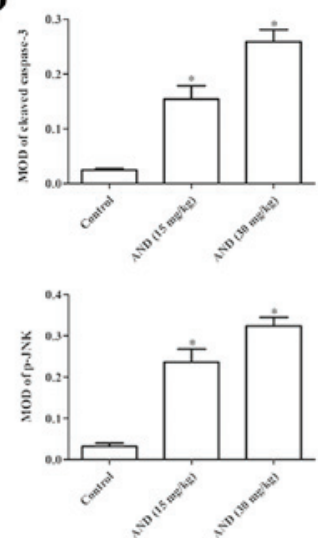

Figure 6. AND induces ROS generation and JNK activation in osteosarcoma cells in vivo. (A) In vivo production of ROS was determined by immunofluorescence using DHE. Scale bar, $50 \mu \mathrm{m}$. (B) Levels of cleaved caspase-3, p-JNK and JNK were determined by western blot analysis. (C) Histology was evaluated using H\&E staining. Cleaved caspase-3 and p-JNK expression levels were measured using immunohistochemistry. Representative images are presented. Scale bar, $100 \mu \mathrm{m}$. (D) Mean optical density of cleaved caspase-3 and p-JNK. "P<0.05 vs. control. AND, andrographolide; ROS, reactive oxygen species; DHE, dihydroethidium; H\&E, hematoxylin and eosin; p-, phospho. 
A

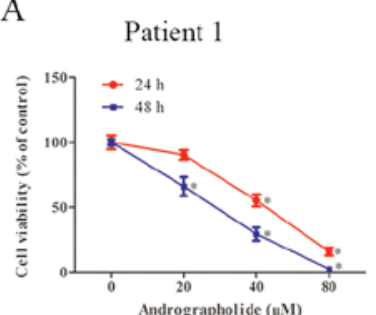

Patient 3

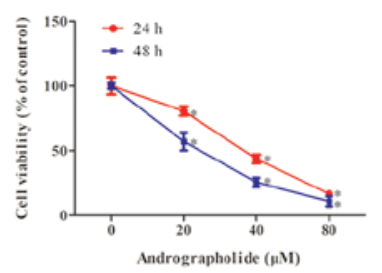

Patient 2

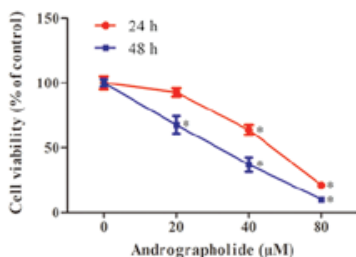

Patient 4

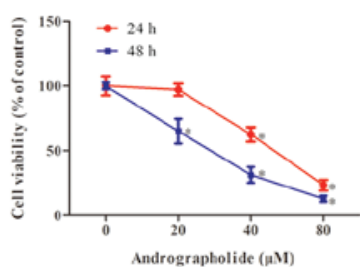

Patient 5

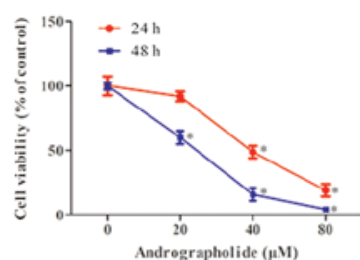

Patient 6

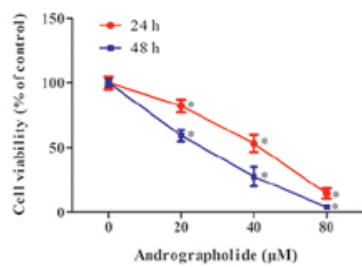

C

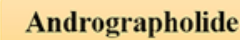

Andrographolide

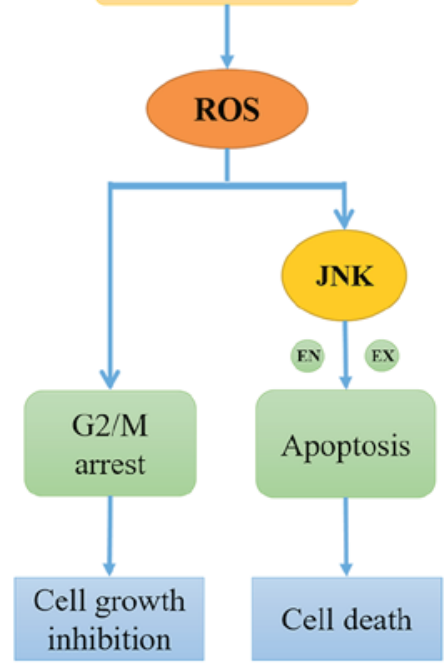

B
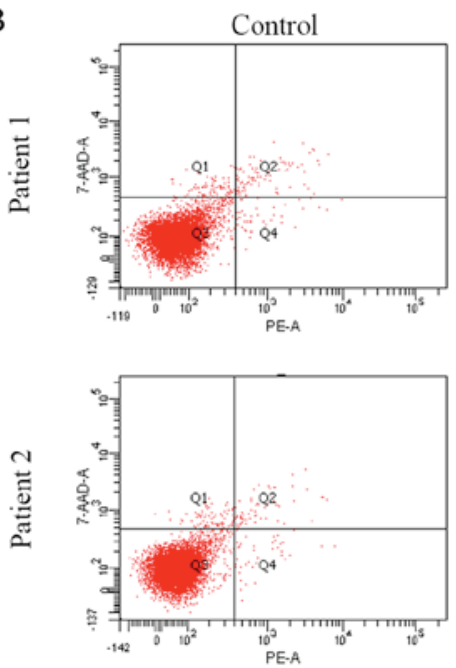
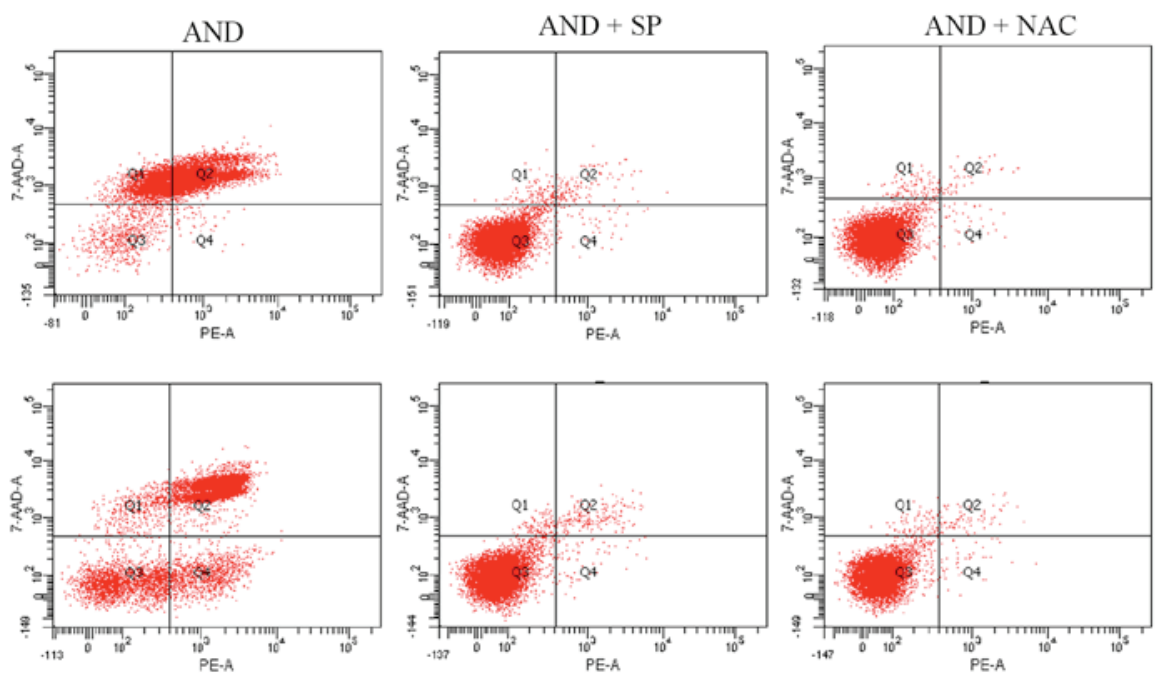

Figure 7. AND exerts a similar antitumor effect on primary osteosarcoma cells as it does on cell lines. Tumor cells derived from osteosarcoma patients were treated with SP or NAC for $1 \mathrm{~h}$ prior to incubation with andrographolide. (A) Cell viability was measured using an MTS assay. (B) Cells were stained with Annexin V-PE/7-AAD following treatment with AND, and apoptosis was evaluated using flow cytometry. ${ }^{*} \mathrm{P}<0.05$ vs. control. (C) Schematic diagram of the pathways in which andrographolide reduced cell growth and increased cell death in osteosarcoma cells. EN, endogenous; EX, exogenous; AND, andrographolide; NAC, N-Acetyl-L-cysteine; SP, SP600125.

andrographolide on clinical specimen. The characteristics of the patients from which specimen were obtained are presented in Table SI. Andrographolide significantly inhibited the proliferation of all primary tumor cells (Fig. 7A). Flow cytometry analysis showed there was an increase in the number of apoptotic cells following andrographolide treatment, similar to the results obtained with the cell lines (Fig. 7B). Thus, these results suggest that andrographolide exerts similar effects on primary cells as it does on immortalized cell lines.

\section{Discussion}

The 5-year survival rate for osteosarcoma patients has increased to $>60 \%$ since 1970 s (38). Despite the fact that the prognosis of localized osteosarcoma has significantly improved due to advances in surgery and multiagent chemotherapy, the long-term survival of patients has remained unaltered for several decades (38). Thus, novel treatments are required to improve the outcomes of patients with osteosarcoma. Andrographolide has been reported to be a promising therapeutic for treatment of multiple types of cancer, with potent antitumor effects and minimal toxicity (11,29,39-42). However, little is known about the effects and biochemical mechanisms of action of andrographolide in osteosarcoma. In the present study, the results demonstrated that andrographolide effectively inhibited the growth of osteosarcoma cells in vitro and in vivo through cell cycle arrest at the $\mathrm{G} 2 / \mathrm{M}$ phase and increasing apoptosis, and that these effects were mediated via the ROS/JNK signaling pathway.

Apoptosis, an energy-dependent genetically programmed cell death mechanism, is a major route for the elimination of cancer. Apoptosis can be induced through either the extrinsic or the intrinsic pathway. Caspase-dependent apoptosis is the major form of controlled cell death in cancer cells. The results of the present study indicated that andrographolide induced apoptosis by activating both extrinsic and intrinsic pathways. 
In the present study, andrographolide treatment resulted in the cleavage of caspase- $3,-8$ and -9 , confirming the involvement of caspase-dependent apoptosis in andrographolide-induced cytotoxicity against osteosarcoma cells.

ROS are unstable molecules which contain oxygen, and are predominantly generated by enzymatic activity and organelles, such as the mitochondria, endoplasmic reticulum and peroxisomes (43). ROS can function as key indicators that serve a prominent role in the mediation of both cell survival and death following exposure to various stimuli, including chemotherapeutic agents, radiation, senescence and host defense $(43,44)$. The interaction of ROS with proteins that are involved in cancer generation, survival and metastasis has been previously demonstrated (45). The presence of ROS has been found to increase cell stress and damage, which result in cell death, via a mechanism known as oxidative stress (46). Moreover, ROS can also induce temporary or permanent cell cycle arrest, and act as signaling molecules that lead to enhanced cytotoxicity and apoptosis by increasing oxidative stress $(47,48)$. Thus, intracellular ROS levels have become a key indicator for a number of chemotherapeutic agents in the induction of cancer cell apoptosis (49-51). In the present study, andrographolide significantly increased the intracellular levels of ROS. Furthermore, the andrographolide-induced cell death, increase in apoptosis, loss of MMP and the increase in cleaved PARP and caspase levels were significantly reversed by an ROS scavenger. Additionally, increased levels of ROS production were also detected following andrographolide treatment in vivo. All these data highlight the critical role of ROS in andrographolide-induced cytotoxicity against osteosarcoma cells.

The activation of JNKs is mediated by several stimuli such as heat shock, Fas ligation, oxidative stress and chemotherapeutic agents (52). Oxidative stress strongly associated with elevated levels of ROS. JNK activation can be induced by both exogenous and endogenous ROS (53). In addition, JNK activation serves a pivotal role in the induction of apoptotic cells (54). In the present study, it was demonstrated that treatment with andrographolide significantly increased the expression levels of phosphorylated JNK in osteosarcoma cells. Furthermore, the inhibition of JNK activation attenuated andrographolide-induced cleavage of PARP, caspase-3, -8 and -9, and cell apoptosis. However, the JNK inhibitor failed to block G2/M phase arrest, suggesting that andrographolide-induced cell cycle arrest was modulated by ROS, but not by JNK. Specifically, JNK phosphorylation was significantly inhibited by ROS scavenger, whereas ROS generation was minimally attenuated by the JNK inhibitor, suggesting that ROS activity is a proximal event of JNK. Based on these results, it can be concluded that andrographolide induced the apoptosis of osteosarcoma cells through the ROS/JNK signaling pathway, and that ROS serves a significant role in the modulation of andrographolide-induced G2/M phase cell cycle arrest.

In conclusion, the present study showed that andrographolide inhibited the growth of osteosarcoma cells by causing G2/M phase cell cycle arrest and inducing apoptosis via the ROS/JNK signaling pathway (Fig. 7C). In the animal experiments, andrographolide was shown to exhibit significant antitumor activity with minimal toxicity. To the best of our knowledge, the present study is the first study to demonstrate the antitumor effects and mechanisms of andrographolide against osteosarcoma. However, there are some limitations. Despite significant tumor growth inhibition in the andrographolide-treated group in the animal study, andrographolide failed to completely prevent tumor growth. Further studies are required to explore the combined therapy of andrographolide with other established treatments to enhance the antitumor effects. Additionally, only six clinical specimens from patients with osteosarcoma were used to preliminarily show the potential antitumor effects of andrographolide in primary cells. Larger cohorts are required in future studies to confirm these results. The results of the present study demonstrate that andrographolide may be a promising therapeutic agent for treatment of osteosarcoma and the findings of the present study may contribute to an improved understanding of the benefits and clinical applications of andrographolide therapy.

\section{Acknowledgements}

Not applicable.

\section{Funding}

This study was supported by the National Natural Science Foundation of China (grant no. 81872173), the Medical and Health Science and Technology Plan of the Department of Health of Zhejiang Province (grant nos. WKJ-ZJ-1821 and 2018KY405), Zhejiang Provincial Natural Science Foundation of China (grant nos. LY20H160018, LY19H160045 and LQ20H060006).

\section{Availability of data and materials}

All data generated or analyzed during this study are included in this published article.

\section{Authors' contributions}

PL and SW designed the study. SW, HL, SC and TC performed the experiments. YY assisted with the animal experiments. PL, ZW and ZY analyzed the data. PL and SW wrote this manuscript. All authors read and approved the final manuscript.

\section{Ethics approval and consent to participate}

Specimen collection was approved by the Human Research Ethics Committees of the Second Affiliated Hospital, School of Medicine, Zhejiang University (Hangzhou, China). Written informed consent was obtained from each patient. The animal experiments were approved by the Animal Care and Use Committee of Zhejiang University (Hangzhou, China).

\section{Patient consent for publication}

Not applicable.

\section{Competing interests}

The authors declare that they have no competing interests. 


\section{References}

1. Agarwal M, Anchan C, Shah M, Puri A and Pai S: Limb salvage surgery for osteosarcoma: Effective low-cost treatment. Clin Orthop Relat Res 459: 82-91, 2007.

2. Biermann JS, Adkins DR, Benjamin RS, Brigman B, Chow W, Conrad EU III, Frassica DA, Frassica FJ, George S, Hande KR, et al; National Comprehensive Cancer Network Bone Cancer Panel: Bone cancer. J Natl Compr Canc Netw 8: 688-712, 2010.

3. Ando K, Heymann MF, Stresing V, Mori K, Rédini F and Heymann D: Current therapeutic strategies and novel approaches in osteosarcoma. Cancers (Basel) 5: 591-616, 2013.

4. Harrison DJ, Geller DS, Gill JD, Lewis VO and Gorlick R: Current and future therapeutic approaches for osteosarcoma. Expert Rev Anticancer Ther 18: 39-50, 2018.

5. Bielack S, Carrle D and Casali PG; ESMO Guidelines Working Group: Osteosarcoma: ESMO clinical recommendations for diagnosis, treatment and follow-up. Ann Oncol 20 (Suppl 4) 137-139, 2009

6. Durfee RA, Mohammed M and Luu HH: Review of Osteosarcoma and Current Management. Rheumatol Ther 3: 221-243, 2016

7. Cassileth BR and Deng G: Complementary and alternative therapies for cancer. Oncologist 9: 80-89, 2004.

8. Kaur R, Kapoor K and Kaur H: Plants as a source of anticancer agents. J Nat Prod Plant Resour 1: 119-124, 2011

9. Mayzlish-Gati E, Fridlender M, Nallathambi R, Selvaraj G, Nadarajan S and Koltai H: Review on Anti-Cancer Activity in Wild Plants of the Middle East. Curr Med Chem 25: 4656-4670, 2018

10. Lim JCW, Chan TK, Ng DS, Sagineedu SR, Stanslas J and Wong WS: Andrographolide and its analogues: Versatile bioactive molecules for combating inflammation and cancer. Clin Exp Pharmacol Physiol 39: 300-310, 2012

11. Islam MT, Ali ES, Uddin SJ, Islam MA, Shaw S, Khan IN, Saravi SSS, Ahmad S, Rehman S, Gupta VK, et al: Andrographolide, a diterpene lactone from Andrographis paniculata and its therapeutic promises in cancer. Cancer Lett 420: 129-145, 2018.

12. Pratheeshkumar P, Sheeja K and Kuttan G: Andrographolide induces apoptosis in B16F-10 melanoma cells by inhibiting $\mathrm{NF}-\kappa \mathrm{B}-\mathrm{mediated}$ bcl-2 activation and modulating p53-induced caspase-3 gene expression. Immunopharmacol Immunotoxicol 34: 143-151, 2012.

13. Huang K, Chen Y, Zhang R, Wu Y, Ma Y, Fang X and Shen S: Honokiol induces apoptosis and autophagy via the ROS/ERK1/2 signaling pathway in human osteosarcoma cells in vitro and in vivo. Cell Death Dis 9: 157, 2018.

14. Zhou J, Zhang S, Ong CN and Shen HM: Critical role of pro-apoptotic Bcl-2 family members in andrographolide-induced apoptosis in human cancer cells. Biochem Pharmacol 72: $132-144,2006$

15. Cheung HY, Cheung SH, Li J, Cheung CS, Lai WP, Fong WF and Leung FM: Andrographolide isolated from Andrographis paniculata induces cell cycle arrest and mitochondrial-mediated apoptosis in human leukemic HL-60 cells. Planta Med 71: $1106-1111,2005$

16. Wong HC, Wong CC, Sagineedu SR, Loke SC, Lajis NH and Stanslas J: SRJ23, a new semisynthetic andrographolide derivative: In vitro growth inhibition and mechanisms of cell cycle arrest and apoptosis in prostate cancer cells. Cell Biol Toxicol 30: 269-288, 2014

17. Burgess DJ: Apoptosis: Refined and lethal. Nat Rev Cancer 13: 79, 2013.

18. Zimmermann KC, Bonzon C and Green DR: The machinery of programmed cell death. Pharmacol Ther 92: 57-70, 2001

19. Fruehauf JP and Meyskens FL Jr: Reactive oxygen species: A breath of life or death? Clin Cancer Res 13: 789-794, 2007.

20. Pelicano H, Carney D and Huang P: ROS stress in cancer cells and therapeutic implications. Drug Resist Updat 7: 97-110, 2004.

21. Wang G, Zhang T, Sun W, Wang H, Yin F, Wang Z, Zuo D, Sun M, Zhou Z, Lin B, et al: Arsenic sulfide induces apoptosis and autophagy through the activation of ROS/JNK and suppression of Akt/mTOR signaling pathways in osteosarcoma. Free Radic Biol Med 106: 24-37, 2017

22. Smolensky D, Rhodes D, McVey DS, Fawver Z, Perumal R, Herald $\mathrm{T}$ and Noronha L: High-Polyphenol Sorghum Bran Extract Inhibits Cancer Cell Growth Through ROS Induction, Cell Cycle Arrest, and Apoptosis. J Med Food 21: 990-998, 2018
23. Li H-Y, Zhang J, Sun L-L, Li BH, Gao HL, Xie T, Zhang N and Ye ZM: Celastrol induces apoptosis and autophagy via the ROS/JNK signaling pathway in human osteosarcoma cells: An in vitro and in vivo study. Cell Death Dis 6: e1604, 2015.

24. Jian SL, Chen WW, Su YC, Su YW, Chuang TH, Hsu SC and Huang LR: Glycolysis regulates the expansion of myeloid-derived suppressor cells in tumor-bearing hosts through prevention of ROS-mediated apoptosis. Cell Death Dis 8: e2779, 2017.

25. Zeng KW, Song FJ, Wang YH, Li N, Yu Q, Liao LX, Jiang Y and Tu PF: Induction of hepatoma carcinoma cell apoptosis through activation of the JNK-nicotinamide adenine dinucleotide phosphate (NADPH) oxidase-ROS self-driven death signal circuit. Cancer Lett 353: 220-231, 2014.

26. Kyriakis JM, Banerjee P, Nikolakaki E, Dai T, Rubie EA, Ahmad MF, Avruch J and Woodgett JR: The stress-activated protein kinase subfamily of c-Jun kinases. Nature 369: 156-160, 1994.

27. Banerjee M, Chattopadhyay S, Choudhuri T, Bera R, Kumar S, Chakraborty B and Mukherjee SK: Cytotoxicity and cell cycle arrest induced by andrographolide lead to programmed cell death of MDA-MB-231 breast cancer cell line. J Biomed Sci 23: 40, 2016.

28. Wei RJ, Zhang XS and He DL: Andrographolide sensitizes prostate cancer cells to TRAIL-induced apoptosis. Asian J Androl 20: 200-204, 2018.

29. Lim SC, Jeon HJ, Kee KH, Lee MJ, Hong R and Han SI: Andrographolide induces apoptotic and non-apoptotic death and enhances tumor necrosis factor-related apoptosis-inducing ligand-mediated apoptosis in gastric cancer cells. Oncol Lett 13: 3837-3844, 2017.

30. Mao W, He P, Wang W, Wu X and Wei C: Andrographolide sensitizes Hep-2 human laryngeal cancer cells to carboplatin-induced apoptosis by increasing reactive oxygen species levels. Anticancer Drugs 30: e0774, 2019.

31. Zhou J, Lu GD, Ong CS, Ong CN and Shen HM: Andrographolide sensitizes cancer cells to TRAIL-induced apoptosis via p53-mediated death receptor 4 up-regulation. Mol Cancer Ther 7: 2170-2180, 2008.

32. Alzaharna M, Alqouqa I and Cheung HY: Taxifolin synergizes Andrographolide-induced cell death by attenuation of autophagy and augmentation of caspase dependent and independent cell death in HeLa cells. PLoS One 12: e0171325, 2017.

33. Rodríguez-Muela N, Germain F, Mariño G, Fitze PS and Boya P: Autophagy promotes survival of retinal ganglion cells after optic nerve axotomy in mice. Cell Death Differ 19: 162-169, 2012.

34. Li B, Zhu X, Sun L, Yuan L, Zhang J, Li H and Ye Z: Induction of a specific CD8+ T-cell response to cancer/testis antigens by demethylating pre-treatment against osteosarcoma. Oncotarget 5: 10791-10802,2014.

35. Scherz-Shouval R and Elazar Z: Regulation of autophagy by ROS: Physiology and pathology. Trends Biochem Sci 36: 30-38, 2011.

36. Neumann J, Yang Y, Köhler R, Giaisi M, Witzens-Harig M, Liu D, Krammer PH, Lin W and Li-Weber M: Mangrove dolabrane-type of diterpenes tagalsins suppresses tumor growth via ROS-mediated apoptosis and ATM/ATR-Chk1/Chk2-regulated cell cycle arrest. Int J Cancer 137: 2739-2748, 2015.

37. Kamata H, Honda S, Maeda S, Chang L, Hirata H and Karin M: Reactive oxygen species promote TNFalpha-induced death and sustained JNK activation by inhibiting MAP kinase phosphatases. Cell 120: 649-661, 2005.

38. Isakoff MS, Bielack SS, Meltzer P and Gorlick R: Osteosarcoma: Current Treatment and a Collaborative Pathway to Success. J Clin Oncol 33: 3029-3035, 2015.

39. Deng Y, Bi R, Guo H, Yang J, Du Y, Wang C and Wei W: Andrographolide Enhances TRAIL-Induced Apoptosis via p53-Mediated Death Receptors Up-Regulation and Suppression of the NF-kB Pathway in Bladder Cancer Cells. Int J Biol Sci 15: 688-700, 2019.

40. Peng T, Hu M, Wu TT, Zhang C, Chen Z, Huang S and Zhou XH Andrographolide suppresses proliferation of nasopharyngeal carcinoma cells via attenuating NF- $\mathrm{BB}$ pathway. BioMed Res Int 2015: 735056, 2015.

41. Zhang QQ, Ding Y, Lei Y, Qi CL, He XD, Lan T, Li JC, Gong P, Yang X, Geng JG, et al: Andrographolide suppress tumor growth by inhibiting TLR4/NF- $\kappa \mathrm{B}$ signaling activation in insulinoma. Int J Biol Sci 10: 404-414, 2014.

42. Peng Y, Wang Y, Tang N, Sun D, Lan Y, Yu Z, Zhao X, Feng L, Zhang B, Jin L, et al: Andrographolide inhibits breast cancer through suppressing COX-2 expression and angiogenesis via inactivation of p300 signaling and VEGF pathway. J Exp Clin Cancer Res 37: 248, 2018 
43. Cui Q, Wang JQ, Assaraf YG, Ren L, Gupta P, Wei L, Ashby CR Jr, Yang DH and Chen ZS: Modulating ROS to overcome multidrug resistance in cancer. Drug Resist Updat 41: 1-25, 2018

44. Gupta SC, Hevia D, Patchva S, Park B, Koh W and Aggarwal BB: Upsides and downsides of reactive oxygen species for cancer: The roles of reactive oxygen species in tumorigenesis, prevention, and therapy. Antioxid Redox Signal 16: 1295-1322, 2012.

45. Kumari S, Badana AK, G MM, G S and Malla RR: G MM, G S and Malla R: Reactive Oxygen Species: A Key Constituent in Cancer Survival. Biomark Insights 13: 91914689, 2018.

46. Nita M and Grzybowski A: The Role of the Reactive Oxygen Species and Oxidative Stress in the Pathomechanism of the Age-Related Ocular Diseases and Other Pathologies of the Anterior and Posterior Eye Segments in Adults. Oxid Med Cell Longev 2016: 3164734, 2016.

47. Boonstra J and Post JA: Molecular events associated with reactive oxygen species and cell cycle progression in mammalian cells. Gene 337: 1-13, 2004

48. Bridge G, Rashid S and Martin SA: DNA mismatch repair and oxidative DNA damage: Implications for cancer biology and treatment. Cancers (Basel) 6: 1597-1614, 2014.

49. Zhou G-Z, Li A-F, Sun Y-H and Sun G-C: A novel synthetic curcumin derivative MHMM-41 induces ROS-mediated apoptosis and migration blocking of human lung cancer cells A549. Biomed Pharmacother 103: 391-398, 2018.
50. Pardhasaradhi BVV, Ali AM, Kumari AL, Reddanna P and Khar A: Phycocyanin-mediated apoptosis in AK-5 tumor cells involves down-regulation of $\mathrm{Bcl}-2$ and generation of ROS. Mol Cancer Ther 2: 1165-1170, 2003.

51. Deeb D, Gao X, Jiang H, Janic B, Arbab AS, Rojanasakul Y, Dulchavsky SA and Gautam SC: Oleanane triterpenoid CDDO-Me inhibits growth and induces apoptosis in prostate cancer cells through a ROS-dependent mechanism. Biochem Pharmacol 79: 350-360, 2010.

52. Shen HM and Liu ZG: JNK signaling pathway is a key modulator in cell death mediated by reactive oxygen and nitrogen species. Free Radic Biol Med 40: 928-939, 2006.

53. Dhanasekaran DN and Reddy EP: JNK signaling in apoptosis. Oncogene 27: 6245-6251, 2008.

54. Krajarng A, Imoto M, Tashiro E, Fujimaki T, Shinjo S and Watanapokasin R: Apoptosis induction associated with the ER stress response through up-regulation of JNK in HeLa cells by gambogic acid. BMC Complement Altern Med 15: 26, 2015.

(i) (9) This work is licensed under a Creative Commons

Attribution-NonCommercial-NoDerivatives 4.0 International (CC BY-NC-ND 4.0) License. 